\begin{tabular}{lrr}
\hline Volume 22 & Nomor 1, Januari 2021 & Halaman 24-31 \\
URL: https://jurnal.unej.ac.id/index.php/SEMIOTIKA/index & E-ISSN: 2599-3429 & P-ISSN: 1411-5948 \\
\hline
\end{tabular}

\title{
KAJIAN EKSPRESIF TERHADAP NOVEL KEMARAU KARYA A.A. NAVIS
}

\section{A.A. NAVIS' KEMARAU IN EXPRESSIVE APPROACH}

\author{
Galang Garda Sanubari ${ }^{1}$, Titik Maslikatin ${ }^{2 *}$, dan Heru S.P. Saputra ${ }^{3}$ \\ ${ }^{1}$ Alumni Fakultas Ilmu Budaya Universitas Jember \\ ${ }^{2,3}$ Fakultas Ilmu Budaya Universitas Jember \\ *Correponding author: titikunej@gmail.com
}

Informasi Artikel:

Dikirim: 11/8/2020; Direvisi: 25/10/2020; Diterima: 10/12/2020

\begin{abstract}
The object of this research is a novel entitles Kemarau by A.A. Navis. It tells about the life of a middle-aged man who lives in a village. The purpose of this research describes the reality and expressions of the author in his works. The method used is descriptive qualitative. The analysis results show that the author, portrayed at the main character, wants to change people's lives and how perceiving work is collided by their personalities and past experiences. This novel is only explicitly discussing the life of the main character. The story is talking about culture, satire and religious obedience. The results of this research show in the extrinsic (expressive) assessment of literary works, the author's critics about the human behaviour, introduction to several Minangkabau cultures, and A.A. Navis' personal experience
\end{abstract}

Keywords: Dynamic Structuralism, Expressive, Kemarau

\begin{abstract}
Abstrak
Novel Kemarau karya A.A. Navis yang menjadi objek penelitian ini bercerita tentang kehidupan seorang laki-laki paruh baya yang tinggal di sebuah kampung. Tujuan dari penelitian ini untuk mendeskripsikan realitas dan ekspresi pengarang dalam berkarya. Meode yang digunakan adalah deskriptif kualitatif. Hasil analisis menunjukkan pengarang melalui tokoh utama berkeinginannya untuk mengubah cara pandang orang-orang di sekitarnya tentang kerja dan memaknai kehidupan yang terbentur oleh sifat mereka dan masa lalu pribadinya. Secara eksplisit novel ini seperti membahas kehidupan tokoh utama saja. Kenyataannya di balik itu, budaya, sindiran, dan ketaatan beragama dikemas dengan rapi di dalamnya. Maka dari itu penelitian ini menghasilkan pengkajian karya sasra secara ekstrinsik (ekspresif), kritik dari penulis karya terhadap prilaku manusia, pengenalan beberapa budaya Minangkabau, dan pengalaman pribadi A.A. Navis
\end{abstract}

Kata kunci: Ekspresif, Kemarau, Strukturalisme Dinamik

\section{PENDAHULUAN}

Novel Kemarau karya A.A. Navis memiliki ciri khas kuat akan makna dan sindiran terhadap fenomena sosial. Latar musim kemarau berkepanjangan, mengungkapkan usaha tokoh bernama Sutan Duano untuk meyakinkan penduduk kampung agar mau bekerja keras melawan 
kekeringan. Proses penceritaan novel ini mengingatkan kita akan karya lain dari Navis Robohnya Surau Kami. Tidak jauh berbeda, maka kedua karya ini memiliki sindiran yang sama dan menjadikan pola kebiasaan masyarakat sebagai objek dari pengarang. Karya Navis ini, menggambarkan bagaimana penduduk kampung yang umumnya petani menghadapi musim kering yang telah merusak sawah mereka. Warga terlihat putus asa dengan kemarau yang tidak kunjung selesai, sebagai wujud usaha mereka menempuh berbagai cara sesuai dengan apa yang diyakini. Warga kampung melakukan sholat untuk meminta diturunkan hujan, bahkan meminta pertolongan dari orang pintar (dukun) juga telah dilakukan. Tidak ada hasil yang didapatkan. Selain usaha menurunkan hujan, tidak ada lagi usaha yang coba dilakukan warga untuk mengolah lahan persawahan. Hampir semua dari warga hanya pasrah dan memilih untuk tetap tinggal di rumah. Ketika orang-orang kampung mulai pasrah dengan keadaan, kemudian dimunculkan tokoh Sutan Duano sebagai wujud nyata kerja keras yang ingin digambarkan oleh A.A. Navis.

Berdasarkan penjelasan mengenai latar belakang pemilihan objek karya sastra, judul karya sastra, biografi pengarang karya, dan gambaran singkat mengenai novel, maka dipilihlah teori Strukturalisme Dinamik sebagai alat pengkajian. Strukturalisme dinamik dipilih sebagai teori pengkajian karena pengungkapan nilai estetik sastra pada novel tersebut dalam pencarian ketegangan antara unsur intrinsik dan ekstrinsik cukup menarik untuk dikaji. A.A. Navis yang memang dikenal memiliki gaya bercerita yang meletup-letup dan kerap implisit dalam menyampaikan gagasannya disadari betul oleh penulis bahwa diperlukan suatu kajian yang memerlukan interpretasi khusus dari segi intrinsik maupun ekstrinsik. Keistimewaan novel ini ialah penyampaian sindiran yang dilakukan secara halus, cerita yang epik, dan mengandung makna-makna tersirat. Untuk mengkaji tegangan karya sastra dari segi intrinsik maupun ekstrinsik yang telah disebutkan di atas, penulis menggunakan teori lain sebagai alat bantu. Yakni teori "Universe Abrams". Teori ini digunakan dengan 4 pendekatan karya sastra, yaitu: objektif (karya sastra), ekspresif (pengarang), mimetik (realita), pragmatik (pembaca) (Teeuw, 1998:189-190). Khusus pada artikel ini, peneliti tidak menggunakan keempat pendekatan milik M.H. Abrams. Pengkajiannya fokus pada pendekatan ekspresif yang mengungkapkan sudut pandang pengarang karya sastra.

\section{METODE}

Metode adalah suatu cara yang digunakan untuk memahami karya ilmiah. Penggunaan metode yang tepat akan berpengaruh pada keberhasilan penulisan sebuah karya ilmiah. Semi (1993:9) membagi metode penelitian menjadi dua jenis, yaitu metode kuantitatif dan kualitatif. Metode kuantitatif merupakan cara kerja penelitian yang menggunakan angka atau hitungan matematis sebagai jaln untuk mengumpulkan data, sedangkan kualitatif mengutamakan cara kerja berdasarkan analisis secara mendalam terhadap objek kajian secara empiris. Penulisan karya ilmiah ini menggunakan metode kualitatif dan pendekatan ekspresif. Metode kualitatif yang lebih spesifik digunakan yaitu deskriptif kualitatif. 


\section{HASIL DAN PEMBAHASAN}

Novel Kemarau membangun suasana dimana kita dibawa untuk membayangkan kehidupan warga desa yang kolot dengan lagak kebahasaan Melayu mereka. Suasana Melayu khas daerah Sumatra Barat terbangun kuat dalam cerita. Penggunaan sebutan Sutan ${ }^{l}$ di depan nama lelaki menjadi contoh suasana yang dihadirkan A.A. Navis. Penggunaan kata Amak ${ }^{2}$ untuk menggantikan "ibu" menjadi penguat lain latar sosial dalam novel. Satu hal lagi dan itu yang paling kuat adalah penyusunan struktur kalimat yang terasa berbeda dari Bahasa Indonesia secara aturan. Misalnya dialog berikut:

"Habis. Apa untungnya mengambil orang kampung lain jadi orang semenda kita, kalau tidak kuat tulangnya melunyah sawah. Entah rang mana dia, mana kita tahu. Entah di mana sakonya (asal-usul), entah di mana pandan pekuburannya." (Kemarau:41)

Dialog di atas merupakan pembicaraan dari masyarakat desa yang penasaran akan siap itu Sutan Duano. Dia tidak diketahui asal usulnya. Tiba-tiba saja dia datang dan menempati surau. Padahal untuk lelaki yang berusia 40 tahun, tidak wajar jika tinggal di sebuah surau. Hanya orang tua dan sudah merasa sebentar lagi akan meninggal saja yang seharusnya mendiami surau. Tinggalnya dia di surau tidak lain juga untuk melakukan ibadah lebih banyak, karena mengingaat umurnya yang kian menua. Lain cerita dengan Sutan Duano.

Laki-laki yang masih segar tanpa asal-usul yang jelas tiba-tiba datang untuk tinggal di dalam surau. Sebagai wujud untuk menunjukkan eksistensi bahasa Minangkabau, Navis menggunakan kata sako yang dalam novel Kemarau (hal, 41) memiliki arti sebagai asal usul. Contoh lain yang melibatkan kebudayaan Minangkabau sebagai latar belakang penulis adalah sebagai berikut:

“Ah. Nantilah ngomong. Bagaimana kau?” sela orang yang di kanannya. “Aku pas.”

"Bilang dari tadi. Omong ya omong. Main terus juga. Kan main bukan dengan mulut. "Apa kau suka dengan si Gudam maka marah saja padaku, ha?"

"Kalau aku tidak satu suku dengannya, sudah kawin bujang dengn gadis aku dengannya," kata orang itu seray mengempaskan batu dominonya. (Kemarau: 36)

Ada tiga jenis perkawinan yang pantang dilakukan oleh orang Minangkabau. Salah satunya adalah perkawinan sesama suku. Mereka menilai bahwa perkawinan yang dilakukan oleh orang satu suku akan merusak sistem adat. Diketahui bahwa orang-orang Minangkabau menganut sistem matrilineal.

Selain menunjukkan eksistensi bahasa dan budaya Minangkabau, A.A. Navis tidak lupa untuk menunjukkan peringatan kepada pembaca tentang hal yang menurutnya salah. Ekspresi penulis diwujudkan dengan munculnya Sutan Duano. Pola pikir tokoh tersebut menentang pemikiran- pemikiran sederhana warga desa. Lewat Sutan Duano dia berdakwah, menyampaikan nilai kehidupan, dan beragama yang menurutnya benar. Berikut salah satu pandangan orang-orang yang menurutnya tidak benar:

\footnotetext{
${ }^{1}$ su.tan $n$ gelar adat untuk laki-laki Minangkabau (Rusmali dkk, (1985)

2 i.bu $n$ amak; amai; mande; biai; ampu; induak: -- jari ampu jari (Adnan, 2004)
} 
"Tapi, orang tambah tercengan lagi karena sisa umurnya dihabiskannya dengan bekerja keras. Padahal, setiap orang yang mau mendiami sebuah surau adalah untuk menghabiskan umur tuanya sambil berbuat ibadah melulu, sembhayang, zikir, dan membaca Qurean sampai mata menjadi rabun. Memang itulah gunanya surau dibuat orang selama ini." (Kemarau:3-4)

Demikianlah menurut Navis mengenai pola pikir masyarakat, tentang orang yang sudah semakin tua dan tinggal di sebuah surau. Pendapat semacam itu tidak disukai olehnya. Dia menunjukkan dalam hampir seluruh penceritaan di dalam novel, bahwa tidak benar pola pikir demikian. Sebagai seorang pengkritik yang baik, Navis tidak hanya menyampaikan sesuatu yang menurutnya jelek saja. Dia juga menyampaikan solusi, sekaligus contoh hasil dari solusi tersebut.

"Di waktu itulah Sutan Duano memulai suatu kehidupan baru. Beberapa bidang sawah terlantar diminta izin yang punya untuk dikerjakannya. ... Malam-malam ketika orang lagi asyik omong-omong di lepau atau mengikuti kusus, ia membenamkan dirinya mengikisi lumut kulit manis sampai tengah malam. Dan di samping itu ia telah mulai sembhayang dan mempelajari agama melalui buku-buku." (Kemarau:6)

"Tapi, Sutan Duano sudah termasuk jadi orang yang berada di kalangan rakyat di kampung itu. Ia sudah punya sepasang bendi, punya seekor sapi untuk membajak. Karenanya ia telah menjadi orang yang berarti, disegani oleh semua orang tapi bukan karena kayanya. Melainkan karena kebaikan hatinya, dipercaya, dan suka menolong setiap orang yang kesulitan." (Kemarau:7)

Menurutnya, kejayaan suatu nagari tidak tergantung pada luas maupun seberapa suburnya wilayah di sana. Melainkan aktivitas dari warganya masing-masing (Navis, 1984:120). Dia tidak juga menganjurkan manusia untuk pasrah dengan keadaan. Kemarau panjang adalah salah satu ganjalan besar warga desa untuk mengolah sawah. Solusi selalu dapat ditemukan dalam permasalahan sesulit apapun.

Sebagai seorang manusia beragama, Navis cukup mengerti perihal ini. Pemahamannya soal agama juga dia selipkan beberapa kali di dalam cerita Kemarau. Agama bagi Navis bukanlah perantara atau alat untuk memperoleh sesuatu. Sering manusia menginginkan sesuatu, akan tetapi menggunakan agama sebagai landasannya. Ajaran yang digunakan untuk mengatur tata keimanan tidak patut digunakan sebagai alat. Apalagi hanya sebuah pemuas nafsu individual. Setidaknya itulah yang ingin dikatakan oleh Navis lewat kutipan berikut.

"Kenapa tidak ada orang yang datang mengaji tadi?" tanya Sutan Duano kemarin sore pada seorang perempuan yang dijumpainya di jalan.

"Kami malu," jawab perempuan itu dengan sorotan mata yang minta maaf. "Malu? Pada siapa?"

"Ya. Pada Guru." "Kenapa?"

"Kami perempuan di kampung ini suka pada Guru. Kami akan mengikuti segala yang Guru suruhkan. Tapi untuk mengangkut air danau untuk semua sawah itu, kami tidak 
sepakat. Lain halnya kalau untuk sawah Guru seorang. Untuk menyiram sawah datuk Malintang yang pelit itu juga, kami tak mau." (Kemarau: 60)

"Sudah selama itu memberi pelajaran agama, hasilnya ternyata nihil. Perempuan di kampung itu hanya jadi pengikutnya, bukan pengikut ajarannya. Ia tidak suka pada pemujaan orang-orang, ia tidak suka sistem bapakisme yang sudah usang itu. Biarlah mereka tak lagi datang ke suraunya, katanya dalam hati. Kalau kedatangannya bukan karena hendak mempelajari agama." (Kemarau:61)

Navis menyindir keras agama yang hanya diperalat demi keinginan pribadi. Sindiran untuk perempuan-perempuan di kampung yang suka mengaji karena tertarik pada si Guru (Sutan Duano). Mayoritas orang suku Minangkabau merupakan pemeluk agama Islam. Mereka juga dikenal memiliki kesetiaan akan agama dan budayanya. Kesetiaan mereka pada adat diungkapkan oleh mamangan: hiduik dikanduang adaik, mati dikanduang tanah (hidup dikandung adat, mati dikandung tanah). Maknanya adalah bahwa orang-orang Minangkabau sudah mengetahui di mana tempatnya dan tidak akan ada tempat lain (Navis, 1984:86). Satu hal lagi yang tidak diinginkan oleh Navis lewat Sutan Duano.

Membicarakan soal kebiasaan. Navis juga tidak luput mengungkapkan pendapatnya. Tampaknya, dia kurang setuju tentang beberapa kebiasaan . Berikut kutipan dialog yang menunjukkan sikapnya tentang kebiasaan "merantau".

"Sudah yakin benar Sutan akan berhasil lebih baik jika di kota?" tanya Sutan Duano setelah lama berpikir-pikir.

"Keadaan nasib siapa yang tahu.

"Jangan bermain judi dengan nasib, Sutan."

"Aku tidak bermain judi. Kalau di sini sangat sempit hidupku, mungkin di tempat lain

Tuhan membukakan pintu rezeki selapang-lapangnya buatku."

"Di mana Sutan thau rezeki lebih lapang di kota daripada di sini?"

$\cdots$

"Di kampung ini pun setiap orang dapat memperbaiki nasibnya kalau ia giat." (Kemarau:8-9)

Lewat pernyataan Sutan Duano, Navis mencoba menyampaikan pendapat bahwa pergi ke kota bukan jaminan untuk menjadi sukses. Pergi ke tempat lain untuk mencari penghidupan, atau biasa kita sebut dengan merantau adalah kebiasaan dari masyarakat Minangkabau. Perbedaan pendapat Navis yang tidak sesuai dengan budaya Minangkabau tersebut bukan berarti dia tidak setuju sepenuhnya atas kebiasaan tersebut. Dia mencoba untuk menjelaskan pertimbangan tentang apa saja yang bisa terjadi. Merantau bukan satu-satunya cara untuk sukses. Bekerja di kampung halaman pun juga bisa sukses. Asalkan orang tersebut mau untuk bekerja keras. Sutan Duano adalah bentuk solusi dari Navis. Bukan hanya nasib yang tidak menentu keadaannya. Harmonisasi keluarga juga dapat terancam. Bagi seorang yang baru saja berangkat merantau, dapat dipastikan bahwa dia akan meninggalkan anak dan istrinya di kampung. Misalnya saja yang terjadi di dalam cuplikan cerita novel Kemarau berikut: 
"Kami sama-sama bertani dulunya. Tapi kemudian ia merantau ke kota. Enam bulan ia baru di rantau, ia telah sanggup membelikan anak istrinya pakaian yang layak ketika ia pulang. Tapi aku, apa yang telah dapat kuberikan buat istriku, selain anak bertambah setiap tahun?"

"Aku dengar si Mariman itu, selama ini di rantau tak pernah mengirimkan nafkah buat keluarganya."

Sutan Caniago terdiam.

"Itu kan tak bisa dibanggakan. Sutan di sini selalu menghiraukan keluarga Sutan. Meski kain bajunya tak terbelikan, tapi nafkahnya Sutan urus. Itu kan sama saja apa yang diberikan si Mariman kepada istrinya." (Kemarau:11)

Seperti itulah ketakutan yang ada di pikiran Navis. Layaknya kebanyakan hal pada umumnya, merantau juga dapat menghadirkan efek baik dan buruk. Tinggal menunggu saja, efek mana yang lebih dominan. Jika orang pergi merantau kemudian dia sukses, itu merupakan hal yang bagus. Apabila yang terjadi justru sebaliknya, maka tidak beruntung orang tersebut. Memang hasilnya tidak dapat ditebak. Justru karena itulah Navis mengingatkan mereka tentang kerugian yang dapat mereka hadapi. Permasalahan ini dapat disikapi dari sudut pandang lain. Mempertaruhkan nasib terkadang juga membutuhkan perhitungan. Melihat sikap dan gaya pemikiran warga desa, tampak mengkhawatirkan jika mereka harus beradu pikiran dengan orang kota. Belum lagi jika nanati mereka harus menerima kenyataan untuk kembali ke kampung halaman.

Bukan hanya budaya merantau yang dikritik oleh Navis. Dia juga mengkritik kegiatan lain yang menurutnya mubazir. Kegiatan tersebut adalah kenduri turun mandi.

"Aku tidak suka uang setoran ditunggak. Itu sudah perjanjian kita. Dan aku sudah bilang berkali-kali."

"Itulah, Guru. Aku perlukan senja ini datang pada Guru untuk minta maaf. Uang setoran itu diambil istriku kemarin."

"Aku tidak suka uangku digunakan untuk kenduri yang mubazir itu. Agama kita tak ada menyuruhkan kenduri turun mandi itu. Malah haram hukumnya karena keduri itu Uwo sampai menipu uang orang lain.” (Kemarau:50)

Navis berpendapat jika kegiatan tersebut tidak diajarkan oleh agama Islam. Selain tidak diajarkan, kegiatan tersebut dinilai mubazir. Apalagi dalam kasus di atas, supir bendi yang bekerjasama dengan Sutan Duano telah membohonginya. Kenduri yang mubazir dan dibiayai dengan uang hasil berbohong, maka haram hukumnya. Pendapat-pendapat tersebut perlu dibahas lebih rinci. Agama Islam yang tidak mengajarkan kenduri dan menurut Navis adalah kegiatan mubazir. Kenduri menurut KBBI (Kamus Besar Bahasa Indonesia) merupakan perjamuan makan untuk memperingati peristiwa, meminta berkah, dan sebagainya. Kenduri pada mulanya bersumber dari kepercayaan animisme- dinamisme. Sebenarnya tujuan diadakannya hanya untuk mencari hubungan antara manusia dengan Tuhan (Herusatoto, 2001:25). Sebagai bentuk akulturasi antara kepercayaan masyarakat lokal dengan ajaran agama Islam, umumnya kegiatan ini akan banyak ditemui di berbagai suku yang mayoritas beragama Islam. 


\section{SIMPULAN}

Berdasarkan data dan analisis di atas, pendekatan ekspresif pada novel Kemarau lebih mengarah kepada ekspresi pengarang untuk mengenalkan budaya daerahnya serta kritik sosial dan praktik keagamaan. Spekulasi seperti ini didasarkan pada isi konten di dalam cerita. Tidak terdapat satu pun bagian di dalam cerita yang mengungkapkan secara implisit maupun eksplisit soal pribadi penulis.

Navis dengan tegas mengatakan bahwa untuk sukses tidak perlu merantau. Sukses bisa diperoleh di desa sekalipun, asalkan orang itu mau bekerja keras. Pendapat itu tidak hanya rekaan dari peneliti. Navis pernah mengatakan hal yang serupa ketika dia diwawancarai Kompas pada tanggal 12 Februari 1992. Dia juga menyampaikan pendapatnya soal beberapa poin kehidupan bergama. Lewat Sutan Duano, dia mengatakan jika membaca Al-Quran tanpa mengerti maknanya itu kurang pas. Kitab suci umat muslim ini tentu memiliki makna sendiri di balik kata-katanya. Akan tetapi, jika orang yang membacanya tidak mengerti maksudnya maka apa yang dapat dipraktekkan darinya. Pendapat ini diperkuat dengan contoh kasus di dalam novel. Ada seorang Buya ${ }^{3}$ yang mengajarkan tentang pratik zakat. Melihat dari cerita, terdapat kesalahan yang dilakukan oleh Buya tersebut. Seharusnya orang-orang tidak mampu yang harus menerima zakat. Tetapi justru Buya itu sendirilah yang mendapat bergoni-goni beras zakat.

\section{DAFTAR PUSTAKA}

Herusatoto, B. 2001. Simbolisme dalam Budaya Jawa. Yogyakarta: Hanindita Graha.

MacIntyre, A. 1995. 'Is Patriotism a Virtue?'. Dalam Ronald Beiner (ed.). Theorizing Citizenship. (hlm. 208-229). Albany: State University of New York Press.

Nanda, D.I. dan Shofiyah, H. 2019. "Perlawanan Perempuan dalam Novel Cantik Itu Luka Karya Eka Kurniawan: Tinjauan Feminisme Sosialis." SENASBASA (Seminar Nasional Bahasa dan Sastra), 3 (8).

Navis, A. A. 1984. Alam Terkembang Jadi Guru. Jakarta: PT Grafiti Pers.

Navis, A.A. 2018. Kemarau. Jakarta: PT Gramedia Widiasarana Indonesia.

Rusmali. 1985. Kamus Minangkabau-Indonesia. Jakarta: Pusat Pembinaan dan Pengembangan Bahasa Departemen Pendidikan dan Kebudayaan.

Semi, A.M. 1993. Rancangan Pengajaran Bahasa dan Sastra Indonesia. Bandung: Angkasa Raya.

Som, W.S. \& Hasanah, F. 2007. "Representasi Femme Fatale dalam Novel Cantik Itu Luka Karya Eka Kurniawan.” Poetika: Jurnal Ilmu Sastra, 12.

Tarigan, H.G. 2015. Prinsip-prinsip Dasar Sastra. Bandung: Angkasa.

Teeuw, A. 1984. Sastra dan Ilmu Sastra, Pengantar Teori Sastra. Jakarta: Pustaka Jaya.

\footnotetext{
${ }^{3}$ Kata sapaan islami kepada orang tua laki-laki; bapak ) atau (KBBI: Buya bu.ya $\mathrm{n}$ - gelar ulama di ranah Minang; kiai ) adalah sebutan untuk seorang Kiai di Minang. Gelar ini biasanya diberikan kepada orang yang alim dalam ilmu agama.
} 
Kajian Ekspresif terhadap Novel Kemarau Karya A.A. Navis (Galang Garda Sanubari, Titik Maslikatin, dan Heru S.P. Saputra)

Widia https://id.wikipedia.org/wiki/Kota_Padang_Panjang (diakses pada 1 Desember 2019, pukul 10.33). 